\title{
UM ESTUDO PSICANALÍTICO DAS RELAÇÕES ENTRE DEPRESSÕES NEURÓTICAS E DESEJO: APROXIMAÇÕES POSSÍVEIS ${ }^{1}$
}

\author{
FERNANDA DE SOUZA BORGES ${ }^{1}$ \\ PAULO JOSÉ DA COSTA ${ }^{2}$
}

\author{
Fernanda de Souza \\ Borges \\ ${ }^{1}$ UniFil, Professora do \\ Curso de Psicologia, \\ Londrina/Pr, Brasil. \\ Paulo José da Costa \\ 2Universidade Estadual \\ de Maringá (UEM), \\ Professor do \\ Departamento de \\ Psicologia, \\ Maringá/PR, Brasil.
}

\begin{abstract}
RESUMO: Pretende-se neste artigo contextualizar a temática das depressões na neurose no cenário atual e, posteriormente, relacionar o abatimento e a deflação libidinal presentes nestes quadros com a função do desejo. Sugerimos que a depressão participa de uma nova economia libidinal na contemporaneidade. O depressivo contemporâneo vem caracterizando-se cada vez mais por uma posição de desistência dos embates inerentes à condição humana, refugiando-se cada vez mais numa posição protegida e paralisada, mais característica das inibições do que dos sintomas. Temas como os processos narcísicos e do luto surgem como horizonte para pensar as depressões neuróticas na contemporaneidade.
\end{abstract}

Palavras-chave: depressão; desejo; neurose.

\begin{abstract}
A psychoanalytic study of the relationship between neurotic depression and desire: possible approaches. This article is intended to contextualize the issue of depression in the contemporary world in order to highlight the massive contingent of depression in the current scenario as formed by neurotics, and later to relate the depressive dejection and libidinal deflation present in these frames with the function of desire. We suggest that depression takes part in a new libidinal economy nowadays. The contemporary depression is characterized increasingly by a withdrawal position of the conflicts inherent in the human condition, increasingly taking refuge in a protected and paralyzed position more characteristic of inhibitions than the symptoms. Narcissism and mourning are central themes.
\end{abstract}

Keywords: depression; desire; neurosis.

DOI - http://dx.doi.org/10.1590/S1516-14982018003006

Todo o conteúdo deste periódico, exceto onde estiver identificado, está licenciado sob uma Licença Creative Commons (cc by 4.0 )

\footnotetext{
${ }^{1}$ Pesquisa de mestrado financiada pela CAPES.
} 


\section{INTRODUÇÃO}

A depressão tornou-se evidentemente uma das maiores expressões do sofrimento psíquico na contemporaneidade, tendo sido classificada como "a epidemia psíquica das sociedades democráticas" (ROUDINESCO, 2000, p. 17); sintoma social privilegiado na cultura do final do século XX e início do XXI (KEHL, 2002); expressão de sofrimento e denúncia de grandeza comparada apenas à histeria do século XIX (ROUDINESCO, 2000; KEHL, 2009); doença do discurso capitalista (SOLER, 2006); e metáfora do malestar na contemporaneidade (BARBOSA, 2008).

Segundo a Organização Mundial da Saúde (OMS), em 2020 a depressão será a maior causa de incapacitação, sendo considerada mais prejudicial que angina, artrite, asma e diabetes (FLECK et al., 2009), com a perspectiva de que em 2030 será a doença mais frequente no mundo (OMS, 2009). Esse alarme tem sido feito na mídia de maneira geral, em jornais de grande circulação e revistas científicas de diversas áreas da saúde e ciências humanas. Que o homem contemporâneo sofre de um mal-estar generalizado que o abate, desanima e paralisa, não parece passar despercebido por quase ninguém.

O problema desta categoria de sofrimento não é privilégio da depressão e, sim, característica da forma como se organizam e se produzem as nosografias presentes nesses manuais e que norteiam o diagnóstico e tratamento do sofrimento no campo da saúde mental. O primeiro elemento discrepante na utilização desses manuais é o fato de serem estatísticos. Afora isso, as classificações contidas são arbitrariamente definidas pelo agrupamento de traços presentes em diferentes pessoas e condições, sem ênfase sobre a etiologia. Então, o DSM-3 surgiu na década de 80, com o intuito de criar um sistema meramente descritivo, sem compromisso com qualquer teoria psicopatológica, uma classificação convencional, normativa e arbitrária (AGUIAR, 2004; DUNKER, 2012). Daí em diante, produziu-se um inchaço das nosografias presentes nos manuais, que só tende a crescer: o DSM-5 conta com aproximadamente 300 categorias de patologias mentais; o DSM-3 tinha 265 e o DSM-2 apenas 182 (SAFATLE, 2013).

A classificação da depressão como uma entidade clínica única não cabe no arcabouço teórico da psicanálise. Uma vez que seus sintomas ou fenômenos podem ser localizados numa variedade de diagnósticos, o quadro nos obriga a partir na direção que vai dos fenômenos às suas possíveis causações internas, considerando o funcionamento do aparato psíquico. Assim, nesta perspectiva, a depressão, no singular, não existe (SOLER, 2006). Embora, portanto, não seja possível enquadrá-la numa categoria única, autores afirmam que os quadros responsáveis por engordar as estatísticas da depressão são frequentemente constituídos por neuróticos (KEHL, 2009; SOLER, 2006), enquanto as estatísticas de quadros psicóticos pelo mundo permanecem quase inalteradas (ROUDINESCO, 2000; MENDLOWICZ, 2009). Isso nos faz pensar que o grande contingente de deprimidos provenha do campo da neurose na atualidade, o que justifica o interesse em nossa pesquisa pelos deprimidos inseridos no campo da neurose.

Esses neuróticos, deprimidos, o que se passa com eles? Apatia, desânimo, falta de apetite, problemas com o sono, impotência sexual, poucas palavras, falta de sentido, dor de viver, falta de fantasias que sustentem as visões de futuro, sensação de que o tempo que não passa, anulação do desejo, fatalismo, transtornos da imaginação etc. (KEHL, 2009). O quadro é extenso, mas cremos que pode ser resumido numa deflação libidinal do sujeito (SOLER, 2006), consequentemente, uma queda na sua capacidade de desejar e/ou de articular seu desejo às coisas do mundo: trabalho, relacionamentos e arte, entre outras.

Diante da premissa freudiana de que só o desejo é capaz de pôr o aparelho psíquico em ação (FREUD, 1900/1996), a pergunta sobre as relações entre estados depressivos e o desejo se delineou quase que espontaneamente. Afinal, se nesses quadros encontramos uma deflação libidinal e se o responsável pelo movimento psíquico é o desejo, deve haver uma relação estreita entre esses elementos.

A escolha se justifica, na medida em que as manifestações depressivas apontam reiteradamente para uma falha na energia libidinal de um sujeito, uma "impotência vital” (RENAUD, 2002, p. 3, tradução nossa). Impotência que se propaga para todas as áreas da vida comum: trabalho, relacionamentos, sexualidade, apetite, sono. É o "morto-vivo" (SOLOMON, 2002, p. 37) que, estando vivo no corpo, não pode fazer vida com ele. 


\section{DESEJO E APARELHO PSÍQUICO EM FREUD}

Encontramos no Projeto (FREUD, 1950/1996) e na Interpretação dos sonhos (FREUD, 1900/1996), a construção de uma fiç̧̃a teórica - assim Freud a nomeia - denominada aparelho psíquico. Este aparelho funciona primariamente sob o mecanismo reflexo, ou seja, mecanismo que segue o princípio do prazer, buscando eliminar quantidades incômodas de energia que se acumulam ou atingem o organismo vivo (FREUD, 1900/1996; 1911/2004; 1950/1996). No entanto, afirma Freud, "as exigências da vida interferem nessa função simples, e é também a elas que o aparelho deve o ímpeto para seu desenvolvimento posterior" (FREUD, 1900/1996, p. 594).

As exigências da vida citadas por Freud são essencialmente aquelas advindas do interior do corpo e das necessidades vitais. No texto clássico sobre as pulsões, Pulsões e Destinos da Pulsão (FREUD, 1915/2004), observamos que estas constituem uma força constante, proveniente do interior do corpo, que irrita o aparato psíquico fazendo com que se busque alcançar a via da descarga a qualquer custo (de acordo com o princípio do prazer). No entanto, se, para os estímulos do exterior, o organismo vivo se serve do mecanismo reflexo, ele não tem recursos para lidar com os estímulos internos e constantes. Isso só será possível quando esse mecanismo se tornar mais complexo, levando Freud a afirmar que os verdadeiros motores do desenvolvimento de nosso sistema nervoso e mental são as pulsões (FREUD, 1915/2004).

A pulsão enquanto força constante, cuja fonte é endógena, convoca um trabalho psíquico frente à inabilidade do mecanismo reflexo de lidar com ela, exigindo trabalho ao psíquico (idem), trabalho este que implica na inscrição mental das vivências corporais.

A "pulsão" nos aparecerá como um conceito-limite entre o psíquico e o somático, como o representante psíquico dos estímulos que provêm do interior do corpo e alcançam a psique, como uma medida de exigência de trabalho imposta ao psíquico em consequência de sua relação com o corpo. (FREUD, 1915/2004, p. 148).

Em outras palavras, frente ao acúmulo de excitações advindo das necessidades somáticas, a atividade psíquica se forja como recurso interno para lidar com esse acúmulo energético. Porém, para que isso ocorra, é preciso um conjunto de funções atreladas e um tempo de desenvolvimento das mesmas, cujo embrião encontra-se naquilo que Freud denominou vivência de satisfação (FREUD, 1950/1996; 1900/1996).

A vivência de satisfação é descrita por Freud (1911/2004) como um momento decisivo para o desenvolvimento das funções do indivíduo, dentre elas o pensamento, a atenção, a memória etc. É pertinente ressaltar que tal vivência ou experiência não se dá de uma única vez. Ela é repetida por diversas vezes até que possa ter sua eficácia garantida e seus efeitos só se consolidam no tempo do complexo de Édipo, sempre respeitando a lógica que Freud descobriu do a posteriori ou nachträglich.

A vivência de satisfação marca um encontro entre a necessidade do bebê, vivida no corpo, e a resolução do mal-estar. Diante dos estímulos do corpo, ele se põe a fazer movimentos reflexos motores, na tentativa de eliminar tais quantidades, mas, como apontado anteriormente, o movimento reflexo é inútil contra os estímulos internos. Assim, para que a satisfação apareça, faz-se urgente a entrada de um outro humano - Nebenmensch -, promotor da "ação específica" (FREUD, 1950/1996, p. 370), que cessará com o estímulo interno através de seus cuidados, cujos protótipos são a fome e o seio.

O encontro entre a necessidade e o outro culminará na cessação dos estímulos e uma experiência de intenso prazer. $O$ que se produz nesse encontro (repetidas vezes) é uma facilitação mental ou trilhamento (Bahnung) entre um traço de percepção do objeto de satisfação e o traço mnêmico da necessidade corpórea, produzindo assim uma associação entre a necessidade e sua resolução. Na próxima vez que a necessidade se fizer premente, surgirá uma moção psíquica que buscará reinvestir a imagem de objeto para obter a satisfação via alucinação (FREUD, 1950/1996; 1900/1996). Este é o início do trabalho psíquico supracitado, imposto pela pulsão: o trabalho que culmina na produção de uma representação do objeto de satisfação (sustentada pela experiência primeva) e, então, em seu reinvestimento diante da necessidade, caracterizando um movimento chamado desejo, que inicialmente 
produz uma satisfação alucinatória e autoerótica. A representação investida é o representante da pulsão no psiquismo (CAROPRESO, 2009). Afirma Freud:

Uma moção [psíquica] dessa espécie é o que chamamos de desejo; o reaparecimento da percepção é a realização de desejo, e o caminho mais curto para essa realização é a via que conduz diretamente da excitação produzida pelo desejo para uma completa catexia [investimento] da percepção. (...) Logo, o objetivo dessa primeira atividade psíquica era produzir uma "identidade perceptiva" - uma repetição da percepção vinculada à satisfação da necessidade. (FREUD, 1900/1996, p. 595).

Alcançar a identidade perceptiva significa investir tanto na representação a ponto de ela se confundir com a experiência mesma da satisfação com o objeto, o que leva Freud a dizer que essa satisfação inicial é alucinatória. Isso é possível porque a vivência de satisfação deixa uma marca, um traço mnêmico, uma marca imagética. Quando o mal-estar da ausência da mãe aparece, o aparelho é capaz de recuperar o traço, investindo em sua marca mnêmica, produzindo assim uma satisfação alucinatória.

No entanto, a alucinação levada às últimas consequências produz o movimento motor de sucção e esse movimento, que busca satisfação, não pode ser levado a cabo via alucinação, posto que o corpo precisa do alimento e não só de sua imagem. Isso culmina naquilo que Caropreso (2009), apoiada em Freud, nominou uma experiência de desamparo.

Além disso, alucinar o objeto na ausência dele gera gastos desnecessários ao organismo e torna necessária uma segunda atividade, um novo método de satisfação da libido - que será denominado funcionamento secundário. Se, antes, buscava-se via alucinação uma identidade perceptiva, ou seja, reviver a satisfação tal qual anteriormente, repetindo-a alucinatoriamente, agora haverá uma identidade de pensamento, caracterizando o desenvolvimento da atividade de pensar e obtendo por esta via uma satisfação de desejo indireta (FREUD, 1900/1996), não mais alucinatória:

Em vez de alucinar, o aparelho psíquico teve então de se decidir por conceber [vorzustellen] as circunstâncias reais no mundo externo e passou a almejar uma modificação real deste. Com isso foi introduzido um novo princípio de atividade psíquica: não mais era imaginado [vorgestellt] o que fosse agradável, mas sim o real, mesmo em se tratando de algo desagradável. Essa instauração do princípio de realidade mostrou-se um passo de importantes consequências. (FREUD, 1911/2004, p. 66; grifo do autor).

Assim, o princípio de realidade se instala a partir da frustração da satisfação alucinatória do desejo cuja base é pulsional -, demarcando no psiquismo a inexistência de satisfação real e irrestrita (perda do objeto), obrigando o aparelho a contar com a realidade e suas possibilidades de satisfação possível. Isso se dá porque, uma vez que o aparelho tem o pensar como recurso, as condensações e deslocamentos aos quais as representações estão sujeitas acabam por impedir a consecução da identidade tal qual existia na ausência do pensamento.

A atividade de pensamento, segundo Freud, "constitui um caminho indireto para a realização de desejo, caminho esse que a experiência tornou necessário" (FREUD, 1900/1996, p. 595). Ele é a possibilidade não só de representar a presença de um objeto em sua ausência - tal qual a alucinação mas de respeitar o registro dessa ausência; não é mais alucinatório (via identidade perceptiva), é um trabalho em torno da ausência do objeto (via identidade de pensamento). Devido a essa mudança de qualidade, há uma perda de satisfação. Após a entrada do funcionamento secundário e do princípio de realidade não é mais possível atingir a identidade perceptiva, apenas aproximar-se dela. A essa perda de satisfação, damos o nome de objeto perdido e, ao movimento de recuperação desta perda, chamamos desejo.

Quinet afirma que é um postulado fundamental da psicanálise que "a estrutura do sujeito se organiza a partir de um furo. Esse furo organizador na estrutura é correlato do objeto perdido, o que implica que aquilo que poderia dar satisfação ao sujeito é perdido desde sempre como condição necessária ao desejo, que, por definição, é insatisfeito" (QUINET, 2003, p. 87). Isso tem tudo a ver com a entrada da palavra e do pensamento, pois o desejo é o resultado da ação da palavra sobre o corpo, ocasionando a morte do objeto alucinado em prol do objeto pensado, simbólico. Dito de outro modo, o homem civilizado precisa soltar a presa e agarrar a sombra. 
O objeto de satisfação (objeto da identidade perceptiva), perdido para o princípio de realidade, opera no psiquismo exatamente por sua ausência. O objeto em psicanálise é uma representação psíquica. E mais: é devido a essa característica que o objeto é perdido, uma vez que nunca poderá ser recuperado de forma integral à primeira vivência, posto que a representação não é a vivência, e, sim, sua marca. Afirma Freud: "ao ser reproduzida como representação, nem sempre a percepção é repetida fielmente; ela pode ser modificada por omissões, alterada por fusões de elementos diversos" (FREUD, 1925/2011, p. 280).

Isso é de extrema importância para a discussão aqui proposta, uma vez que o desejo será a moção psíquica que busca reinvestir as imagens do objeto de satisfação, sempre produzindo uma satisfação parcial - dada a perda do objeto integral - e sempre deixando uma parcela não identificável entre necessidade e objeto possível, resto que renova as exigências de satisfação ad infinitum. Tal como a figura da fênix, o desejo renasce das cinzas a cada satisfação, e tem o potencial de relançar o humano à frente, conforme nos ensina Freud em Além do princípio do prazer (1920/2010):

O instinto reprimido jamais desiste de lutar por sua completa satisfação, que consistiria na repetição de uma vivência primária de satisfação; todas as formações substitutivas e reativas, todas as sublimações não bastam para suprimir sua contínua tensão, e da diferença entre o prazer de satisfação encontrado e o exigido resulta o fator impulsor que não admite a permanência em nenhuma das situações produzidas, mas, nas palavras do poeta, "sempre impele, indomável, para a frente". (FREUD, 1920/2010, p. 210; grifo nosso).

Aparentemente, nas depressões, há algo que compromete o movimento acima descrito. Afinal, "o estado de desejo ou, em última instância, o desejo insatisfeito pelo desencontro com o objeto que com ele não coincide totalmente manterá o psiquismo em movimento" (EDLER, 2008, p. 80).

\section{DEPRESSÃO E DESEJO}

Freud não escreveu nenhum trabalho em sua obra dedicado à depressão propriamente dita. Embora utilizasse esse termo na descrição sintomatológica de alguns casos - Emmy, Dora, Elizabeth -, não se dedicou ao estudo exaustivo dessa categoria. Na busca por encontrar estados que se assemelhem aos quadros depressivos, começamos pela tríade freudiana inibição, sintoma e angústia. Não raro encontramos autores que tomam os quadros depressivos como sintomáticos, enquanto outros tendem a crer que as manifestações depressivas estão mais próximas da inibição do que do sintoma ou da angústia (KEHL, 2009; PÉRET, 2003; SIQUEIRA, 2006; SOLER, 2006).

Freud (1925/1996) afirma que a inibição é uma perturbação diretamente associada às funções do Eu, quais sejam: as funções sexual, alimentar, de locomoção e do trabalho. Isso corrobora o conhecimento vigente sobre a fenomenologia da depressão: “A depressão é uma condição frequente, em geral recorrente e de curso crônico, associada com níveis altos de incapacitação funcional" (FLECK et al., 2009, p. 7; grifo nosso).

Seguimos com Freud:

Passemos então a descrever a inibição de forma a deixar muito pouca dúvida sobre o que se quer dizer com ela, e digamos que a inibição é a expressão de uma restrição de uma função do ego. Uma restrição dessa espécie pode ter causas muito diferentes. Alguns dos mecanismos em jogo nessa renúncia à função são bem conhecidos por nós, como o é certa finalidade geral que a rege. (FREUD, 1925/1996, p.93; grifo nosso).

Apreendemos da afirmativa freudiana que a inibição não contém em si mesma uma explicação sobre a causa, e, sim, que essa se manifesta como restrição das funções do Eu devido a causas variadas. Além disso, há em jogo uma renúncia à função com determinada finalidade, portanto uma decisão subjetiva inconsciente, que, de acordo com Freud (1925/1996), busca eliminar a angústia ligada à função em questão. Essa renúncia se dá em função de conflitos com as instâncias adjacentes ao Eu: Supereu ou Id. ${ }^{2}$

\footnotetext{
${ }^{2} \mathrm{~A}$ variação na nomenclatura se deve à multiplicidade de traduções presentes nas edições consultadas.
} 
Continuando, há também as inibições generalizadas: assemelham-se aos estados depressivos, uma vez que as funções vitais ficam abaladas em sua totalidade.

Nesse ponto, Freud aponta aparentemente para uma solução econômica para o problema da depressão, uma vez que o estado de inibição generalizada se daria devido ao gasto energético exagerado em determinadas atividades, então empobrecendo o Eu em sua potência vital. Assim, temos as inibições, ora como medidas de precaução e evitação de conflitos, ora como resultado de um empobrecimento da energia disponível ao Eu (FREUD, 1925/1996).

Nas inibições generalizadas, Freud (idem) apontou como possíveis causas desses estados: processos de luto, supressão intensa do afeto, e controle dos desejos sexuais. Todos esses elementos apontam para conflitos intrapsíquicos entre interesses de diferentes instâncias. Na inibição, Freud (idem) afirma estar em ação uma renúncia, que podemos supor desejante, devido à recusa no enfrentamento dos conflitos, uma vez que, conforme demarcou, a inibição se dá na recusa de possíveis conflitos com o Supereu ou com o ld: "A depressão evoca uma posição do sujeito de fuga, de não querer saber daquilo que o afeta" (PÉRET, 2003, p. 22). De acordo com Edler, nas depressões encontramos um sujeito em posição de desistência e o "abandono do desejo implica algum grau de traição consigo mesmo e, nesse contexto, não é raro o aparecimento da culpa" (EDLER, 2008, p. 85). Isso levou Lacan a afirmar que, nas depressões, temos uma posição de covardia moral (KEHL, 2009). Trata-se aqui de sair em retirada de um encontro sempre marcado com o inconsciente: "Não queres saber nada do destino que o inconsciente cria para ti?" (LACAN, 2003, p. 541).

Vejamos o que Freud nos fala sobre Miss Lucy, uma das histéricas dos Estudos sobre a histeria, quanto à sua posição frente aos conteúdos inconscientes:

Assim, o mecanismo que produz a histeria representa, por um lado, um ato de covardia moral e, por outro, uma medida defensiva que se acha à disposição do ego. Com bastante freqüência temos de admitir que rechaçar as excitações crescentes provocando a histeria é, nessas circunstâncias, a coisa mais conveniente a fazer; com maior freqüência, naturalmente, temos que concluir que uma dose maior de coragem moral teria sido vantajosa para a pessoa em causa. (FREUD; BREUER, 1893/1996, p. 149; grifos nossos).

Aqui, Freud (1925/1996) retifica sua posição quando aponta para a responsabilidade moral pelo conteúdo dos sonhos, ou seja, mesmo que nada se saiba, há uma responsabilidade daquele que deseja e é a essa responsabilidade que o depressivo se furta a todo custo, pois o que se revela aqui é que, diante dos conflitos com as instâncias do aparelho psíquico, ao invés de um acordo - como encontramos nas formações sintomáticas - a inibição representa uma paralisia, uma espécie de desistência de levar a cabo o desejo em jogo, mesmo que por vias substitutas.

\section{O LUTO ENQUANTO MODELO PARA PENSAR OS ESTADOS DEPRESSIVOS E A INIBIÇÃO}

Freud (1925/1996) apontou também o luto como causa metapsicológica da inibição e empobrecimento do Eu e, para tal, recorremos ao clássico texto Luto e melancolia (FREUD, 1917/2010). Neste ensaio, encontramos duas reações à perda, seja esta de natureza material ou ideal: luto e melancolia. Aqui, o processo do luto se aproxima bastante com a descrição fenomenológica de Freud sobre a melancolia, que inclui o empobrecimento do Eu e identificação deste com o objeto perdido. $O$ que serviu de balizamento nessa pesquisa foi, conforme apontado anteriormente, o dignóstico diferencial e estrutural, para o qual, apesar de gerar controvérsias, a melancolia está mais próxima da psicose. Isso se deve a certa confusão entre o sujeito e o objeto perdido, ocasionando que, na perda do objeto, haja também perda de parte de si mesmo. Valorizou-se o processo de luto por julgá-lo mais próximo dos quadros neuróticos - onde, apesar de perder também algo de si, o neurótico não se confunde com o objeto - e devido ao apontamento freudiano que aponta o luto na origem de algumas inibições generalizadas. Ressaltamos que a discussão diagnóstica diferencial entre luto e melancolia é extensa e que não se pretende esgotar a discussão neste artigo. 
Que uma pessoa pareça deprimida quando está de luto não é novidade, porém, nesse sentido, queremos investigar se nos casos depressivos podemos utilizar o modelo do luto para compreensão e tratamento da depressão em sua relação com o desejo.

Vejamos, o luto é um trabalho doloroso, que consiste na retirada gradual da libido de objetos perdidos. É um trabalho bastante árduo, pois "o ser humano não gosta de abandonar uma posição libidinal, mesmo quando um substituto já se anuncia" (FREUD, 1917/2010, p. 173). Ou seja, o luto consiste em aceitar, mediante os imperativos da realidade, a perda do objeto e sua característica fenomenológica se deve muito provavelmente ao empobrecimento dos interesses do Eu pelo mundo durante o trabalho de aceitação da perda. Uma vez aceita a perda, o luto se desvanece e a libido pode investir novamente em objetos. Os objetos nos quais a libido é investida são construídos ao longo da história individual de cada sujeito, sendo estes substitutos do objeto perdido primordialmente. Nessa perspectiva, o objeto permite uma organização da libido em torno dele e a perda de um objeto amoroso tem consequências, dentre elas, a desorganização pulsional ocasionada pela perda do referente libidinal.

De acordo com Tavares (2010) o trabalho do luto consiste em: teste de realidade; retirada gradual da catexia do objeto perdido; e, por fim, reinvestimento libidinal em objetos substitutos. Nasio (1997), em seu Livro da dor e do amor, aponta um elemento intermediário nesse processo, que geralmente passa despercebido pelos leitores de Freud: o superinvestimento nas representações do objeto perdido antes da retirada da catexia.

Segundo Nasio (1997), em Luto e melancolia há uma segunda nuance de fundamental importância, que é a afirmativa freudiana de que o doloroso neste processo é o trabalho do luto e não a perda do objeto. $O$ trabalho do luto é uma reação à perda. O autor recupera a noção em Freud de que a dor corporal decorre de um hiperinvestimento, uma excitação que rompe o escudo protetor do pára-excitações e, a partir disso, afirma que a dor do luto decorre principalmente da intensa ligação às representações do objeto perdido que procedem à perda. "Conclusão: a dor do luto não é dor de separação, mas dor de ligação (...) o que dói não é separar-se, mas apegar-se mais do que nunca ao objeto perdido" (NASIO, 1997, p. 166; grifo do autor). Desta feita, a dor seria de apertar demais os laços com o objeto ausente.

Sabemos que, no processo de luto, está intrinsecamente implicada a função da perda. Afirmamos que o investimento da libido nos objetos caracteriza aquilo que chamamos de movimento do desejo. $\mathrm{Na}$ neurose, há no curso do complexo de Édipo a instalação da perda do objeto primordial e consequente reorientação da libido para os objetos tolerados e permitidos pela realidade, o que implica necessariamente no abandono do objeto alucinado em prol dos objetos substitutos. Com o luto, não é diferente: se não houver o abandono do objeto - que neste caso assemelha-se ao alucinado, no sentido de que há a manutenção de um vínculo que quase renega a realidade dos fatos - o desejo não poderá investir em novos objetos. Isso nos permite afirmar, com cautela, que no luto há uma inibição do desejo, tal qual o compreendemos na neurose, devido ao hiperinvestimento no objeto "alucinado", ou seja, cujo referente na realidade já não se encontra mais. Essa tendência levada às últimas consequências assemelha-se ao estado de catatonia, exemplo de realização alucinatória de desejo que não se dirige ao mundo externo (TEIXEIRA, 2012).

Desta feita, o movimento do desejo só se mostra possível dada a perda do objeto primordial e consequente direcionamento da libido para objetos substitutivos. No luto, o sujeito revive uma perda e um luto primordial e é convocado a pôr em prática aquilo que aprendeu com essa perda. Freud nos ensina que o luto pode ser de um ideal, uma abstração. Seguindo nosso pensamento hipotético-dedutivo, podemos afirmar, então, que os ideais - privilégios narcísicos - quando perdidos, nas neuroses, tendem a produzir efeitos de luto? Trata-se de um luto de Narciso? Retomando, resta a questão sobre os efeitos de luto diante das perdas de ideais narcísicos.

\section{NARCISISMO, DESEJO E ESTADOS DEPRESSIVOS}

O narcisismo constitui um dos pilares fundamentais da constituição da subjetividade. É um tempo onde se ergue uma imagem de si, sempre alienada na imagem do outro cuidador e em seu discurso. Aquele que, com seu próprio ideal narcísico, toma um filho em seus cuidados transmite a ele 
especularmente um lugar no mundo. Garcia-Roza aponta que, sob a denominação "narcisismo", há certa modulação na obra freudiana e "somente a partir de 1914 que a noção de narcisismo adquire um estatuto conceitual compatível com sua importância no conjunto da teoria psicanalítica" (GARCIA-ROZA, 2011, p. 46).

A noção de narcisismo marca o nascimento do Eu na relação com o Outro, da linguagem e outro semelhante. É nesse encontro com o semelhante que ela poderá identificar-se a algo e assim iniciar a construção de seu ser. Parafraseando Freud, podemos dizer que esse momento é a pedra angular do ser, o nascedouro de um sujeito psíquico.

Jacques Lacan utilizou uma noção que ficou conhecida como "estádio do espelho", que em sua noção mais simples - porém correta - significa o momento de apreensão que toda criança pequena, entre 6 e 18 meses, precisa ter de sua própria imagem diante do espelho (CABAS, 1982).

Para além da leitura concreta de uma criança diante de um espelho, o que Lacan assinalou é que o espelho ultrapassa o vidro refletor; o espelho é a mãe, seu desejo. É o momento de estabelecer uma relação recíproca, onde o desejo da mãe fisga o bebê. É exatamente neste ponto que a maioria dos autores desse trabalho, independente de sua orientação teórica dentro da psicanálise, concorda que, havendo falha na atribuição narcísica da mãe ao bebê, ou seja, em seu desejo, haverá graves consequências de fenomenologia depressiva.

Haverá, pois, nesse entrecruzamento de olhares entre mãe e bebê, a produção de uma organização corporal. Lembremos que a criança pequena está envolta num turbilhão de excitações provindas das fontes mais variadas da pulsão e também do mundo externo. Segundo Cabas (1982), há uma vivência nesse momento de pluralidade e fragmentação corporal, devido à parcialidade da pulsão. Será o desejo da mãe, naquilo que se apodera dessa criatura, que poderá produzir uma ideia de unidade para o corpo despedaçado.

Freud afirma que "o Eu é sobretudo corporal, não é apenas uma entidade superficial, mas ele mesmo a projeção de uma superfície" (FREUD, 1923/2011, p. 32). Completa Freud em nota de rodapé que o Eu deriva das sensações corporais e constitui "a projeção mental da superfície do corpo" (idem, n. 1; grifo nosso). Ou seja, o corpo é uma projeção mental, é o corpo inscrito no psiquismo e essa projeção assemelha-se a uma unidade, produzindo um apaziguamento das moções pulsionais fragmentadas, sendo concomitante a esse processo a formação da instância psíquica do Eu.

Esse momento é marcado pela onipotência jubilatória de sua majestade, o bebê (FREUD, 1914/2010). A essa instância chamaremos mais especificamente de Eu-ideal (Ideal Ich), pois será necessário fazer a distinção dela com o Ideal do eu (Ich Ideal). No texto freudiano, essa noção diferencial não é tão clara, Garcia-Roza (2011) aponta que, quando da tradução do alemão para o inglês e depois para o português, os termos foram traduzidos de forma igual por "Ideal do eu", apagando a nuance do texto freudiano. 0 Eu-ideal é então o Eu narcísico, alienado na imagem de completude, enquanto o Ideal do eu é a instância oriunda, tal qual o Superego, do complexo de castração e, representa a castração e uma reação contra ela. A essa alienação na imagem ideal - Eu-ideal - Pinheiro, Quintella e Verztman (2010) chamaram de "crença narcísica" e Monti (2008) chamou de "contrato narcisista".

O Ideal, então, além de conter em sua origem os ideais narcísicos infantis, ou seja, o Eu-ideal, é uma instância que tem na sua origem a introjeção da perda de objetos incestuosos e representa a saída do conflito edipiano, via objetos substitutos, uma vez que os objetos originais estão para sempre perdidos.

O chamado ideal do eu é o que, em Freud, apresenta-se como movimento subjetivo a partir do qual o sujeito se inscreve no universo desejante, na medida em que abandona sua "megalomania infantil" - esta sugestiva de uma busca pela satisfação sumária e imediata de todos os anseios narcísicos. Ao abandonar a crença narcísica, o sujeito organiza para si uma forma de satisfação submetida ao ideal do eu, cuja referência acha-se conjugada à própria organização da cultura. (QUINTELLA, 2008, p. 93).

Aqui, retornamos à questão depressiva. Pinheiro, Quintella e Verztman (2010) afirmam que "é preciso frisar, sob esse parâmetro, que não é a perda em si que determinará um estado depressivo crônico ou agudo; o que vai precisamente definir ou não o mergulho em sua estagnação depressiva grave ou 
crônica é a forma como o sujeito dará encaminhamento subjetivo à experiência de perda" (QUINTELLA, 2008, p. 135). Ou seja, em última análise, não se trata da natureza da perda e, sim, da posição frente a ela.

Com isso, o autor quer demonstrar que, antes, a infância estava permeada de elementos trágicos, e que, hoje, a cultura da infância encaminha-se para um culto, uma "monumentalização da infância" (MONTI, 2008, p. 245). Segundo essa lógica, estaríamos vivendo culturalmente um incentivo ao culto de "Sua Majestade, o bebê", o que teria efeitos sobre o lugar do filho na família e dificultaria a transmissão dos fatos da castração, dos limites, das regras e da morte, consequentemente, imobilizando o movimento desejante. Isso levou Pinheiro, Quintella e Verztman (2010) a afirmar que esses sujeitos depressivos são sujeitos referenciados na crença narcísica e que a depressão contemporânea é uma das vicissitudes dessa crença. Mas qual a relação entre estar referenciado no narcisismo do Eu-ideal e deprimir-se?

Monti destaca aí o ponto preciso do sofrimento depressivo e contemporâneo quando afirma que "um trono do qual não se pode descer é mais uma armadilha do que um trono" (MONTI, 2008, p. 245). Vejamos: estamos afirmando que o depressivo neurótico contemporâneo sofre porque está assentado em seu narcisismo e que isso paralisa seu movimento de desejo, posto que, se o luto não se faz, os investimentos ficam paralisados no objeto ou na crença perdida. "Frisa-se nesse contexto, a partir do pensamento de Freud, que a abertura ao jogo da vida e do desejo exige que o sujeito inscreva-se como transitório, mutável, descentrado e mortal" (PINHEIRO, et al., 2010, p. 158).

Segundo Kehl (2009), na etiologia das depressões crônicas, há um agravante quanto aos enfrentamentos dos conflitos acima mencionados, pois haveria nesses casos uma presença materna excessiva, hipersolícita, o que faria com que, nos cuidados com a criança, essa mãe apresentasse a satisfação antes do tempo vazio necessário ao enfrentamento do mal-estar pelas próprias ferramentas da criança. Isso teria com consequência a instalação de um trabalho psíquico empobrecido, dificultando os embates desse sujeito com situações onde a castração se apresenta e favorecendo sua reclusão numa posição infantil e narcísica.

A problemática acima ganha força quando adentramos no funcionamento contemporâneo. Sugere Quinet que "a sociedade regida pelo discurso capitalista se nutre pela fabricação da falta de gozo, produz sujeitos insaciáveis em sua demanda de consumo" (QUINET, 2006, p. 39). Pode-se dizer que é um efeito imaginário de completude, que tem como corolário o surgimento da satisfação sem mediação simbólica: angústia, paralisia, morte. Assim, a depressão, juntamente com outras formas de sofrimento no contemporâneo, faz parte de um grupo de efeitos da paralisia do desejo, que ora podem ser de paralisia expressa, ora se transvestem de toxicomanias e outros tipos de adicções.

\section{CONSIDERAÇÕES FINAIS}

Apresentamos uma variedade de maneiras de recusar as perdas, que vão desde o luto propriamente dito a inibições e tentativas de recuperação narcísica que paralisam as escolhas de desejo. Todo nosso esforço foi para demonstrar o valor da castração enquanto motor dos movimentos desejantes que empurram um sujeito na vida, e que a referência à perda é responsável por manter o circuito do desejo ativo. Quando essa referência é reduzida, escamoteada, apagada, os efeitos são mortíferos; os sujeitos não sentem a vida passar, a memória fragiliza, a vida perde a graça.

O trabalho analítico deve ter no horizonte o objetivo de restaurar as relações da neurose com o vazio deixado pelo objeto, substituindo o vazio, que é ferida narcísica e paralisa, por uma referência ao vazio como causa do desejo e motor das atividades, possibilitando a satisfação das exigências pulsionais por vias menos tóxicas e mortíferas. Esse é o destino da cura analítica: assimilar a falta para fazer dela o âmago do ser, causa do movimento, chance, aposta. Para fazer uma aposta, é preciso contar com uma perda logo na saída: essa é a aposta do analista. O que uma psicanálise ensina? Que nesta vida quem perde, ganha.

Recebido em: 12 de junho de 2016. Aprovado em: 27 de novembro de 2016. 


\section{REFERÊNCIAS}

AGUIAR, A. A. A psiquiatria no divã: entre as ciências da vida e a medicalização da existência. Rio de Janeiro: Relume Dumará, 2004.

BARBOSA, S. R. C. S. Transformações sócio-culturais contemporâneas e algumas implicações nos diagnósticos na área de saúde mental. Mudanças - Psicologia da Saúde. 16(1), 2008, 1-9.

CABAS, A. G. Curso e discurso da obra de Jacques Lacan. São Paulo: Moraes, 1982.

CAROPRESO, F. Dor e desejo na teoria freudiana do aparelho psíquico e das neuroses. Revista de Filosofia Aurora, 21(29), 2009, 569-590.

DUNKER, C. O sequestro da neurose. Revista Cult, n. 184, 2012. Disponível em: <https://pt.scribd.com/document/320196077/DOC-2015-O-Sequestro-Da-Neurose> Acesso em: 21 jul. 2018.

EDLER, S. Sobre o desejo: estados depressivos e sua relação com o desejo. In: Luto e melancolia: à sombra do espetáculo. São Paulo: Civilização Brasileira, 2008. p. 75-87.

FERREIRA, M. C. S. Suicídio, da identificação com a mãe morta ao resgate narcísico: um estudo psicanalítico do personagem Richard Brown do filme As horas. Disertação de Mestrado do Programa de Pós-Graduação em Psicologia Clínica e Social da Universidade Federal do Pará, Belém, 2007. Inédita.

FLECK, M. P. A., et al. Diretrizes da Associação Médica Brasileira para o tratamento da depressão (versão integral). Revista Brasileira de Psiquiatria, 25(2), 114-122. Disponível em: < http://www.scielo.br/scielo.php?script=sci_arttext\&pid=S1516-

$44462003000200013 \&$ lng=en\&nrm=iso\&tlng=pt >. Acesso em: 21 jul. 2018.

FREUD, S. Além do princípio do prazer (1920). Rio de Janeiro: Imago, 2010. (Obras psicológicas de Sigmund Freud, 14).

Algumas notas adicionais sobre a interpretação dos sonhos como um todo (1925). Rio de Janeiro: Imago, 1996a. (Ed. standard brasileira das obras completas, 19).

16). A negação (1925). Rio de Janeiro: Imago, 2011. (Obras psicológicas de Sigmund Freud,

FREUD, S.; BREUER, J. Estudos sobre a histeria (1893). Rio de Janeiro: Imago, 1996. (Ed. standard brasileira das obras psicológicas completas de Sigmund Freud, 2).

FREUD, S. Conferências introdutórias sobre psicanálise (parte III): Conferência XXIII (1917). Rio de Janeiro: Imago, 1996a. (Ed. standard brasileira das obras completas, 16).

. Formulações sobre os dois princípios do acontecer psíquico (1911). Rio de Janeiro: Imago, 2004. (Obras psicológicas de Sigmund Freud: escritos sobre a psicologia do inconsciente, 1).

. Inibições, sintomas e ansiedade (1925). Rio de Janeiro: Imago, 1996a. (Ed. standard brasileira das obras completas, 20 ).

Introdução ao Narcisismo (1914). Rio de Janeiro: Imago, 2010. (Obras psicológicas de Sigmund Freud, 12).

. Interpretação dos sonhos (1900). Rio de Janeiro: Imago, 1996a. (Ed. standard brasileira das obras completas, 5). Freud, 12).

Luto e melancolia (1917). Rio de Janeiro: Imago, 2010. (Obras psicológicas de Sigmund

O Eu e o Id (1923). Rio de Janeiro: Imago, 2011. (Obras psicológicas de Sigmund Freud,

16). Freud, 12).

O inconsciente (1915). Rio de Janeiro: Imago, 2010. (Obras psicológicas de Sigmund

Projeto para uma psicologia científica (1950). Rio de Janeiro: Imago, 1996a. (Ed. standard brasileira das obras completas, 1$)$.

Pulsões e destinos da pulsão (1915). Rio de Janeiro: Imago, 2004. (Obras psicológicas de Sigmund Freud: escritos sobre a psicologia do inconsciente, 1 ).

GARCIA-ROZA, L. A. Introdução à metapsicologia freudiana (v. 3). Rio de Janeiro: Jorge Zahar, 2011.

KEHL, M. R. O tempo e o cão: a atualidade das depressões. São Paulo: Boitempo, 2009.

Sobre ética e psicanálise. São Paulo: Companhia das Letras, 2002.

LACAN, J. Televisão. In: Outros escritos. Rio de Janeiro: Jorge Zahar, 2003.

MONTI, M. R. Contrato narcisista e clínica do vazio. Revista Latinoamericana de Psicopatologia Fundamental, n. 11(2), 2008, p. 239-253. 
MORAES, A. A. R. E. A contribuição winnicottiana para a teoria e clínica da depressão. Tese de Doutorado. Programa de Pós-Graduação em Psicologia Clínica da Pontifícia Universidade Católica de São Paulo, São Paulo, 2005. Inédita.

NASIO, J-D. O livro da dor e do amor. Rio de Janeiro: Jorge Zahar, 1997.

OMS: Depressão será doença mais comum do mundo em 2030. (2 de setembro de 2009). Disponível em: <http://www.estadao.com.br/noticias/geral,oms-depressao-sera-doenca-maiscomum-do-mundo-em-2030,428526,0.htm>. Acesso em: 3 maio 2013.

PÉRET, M. F. F. A depressão na clínica lacaniana: um estudo de caso. Dissertação de Mestrado. Programa de Pós-Graduação em Psicologia da Universidade Católica Dom Bosco, Mato grosso do Sul, Campo Grande. Inédita.

PINHEIRO, M. T. S, et al. Distinção teórico-clínica entre depressão, luto e melancolia. Psicologia Clínica, n. 22(2), 2010, p. 147-168.

QUINET, A. Psicose e laço social: esquizofrenia, paranoia e melancolia. Rio de Janeiro: Jorge Zahar, 2006.

QUINTELA, R. R. Vicissitudes da crença narcísica: a depressão no mundo contemporâneo. Tese de doutorado. Programa de Pós-Graduação em Teoria Psicanalítica da Universidade Federal do Rio de Janeiro, Rio de Janeiro. 2008. Inédita.

RENAUD, A. Dépression, inconscient et vie psychique: pas si mêlant que ça! $14^{e}$ journée RolandSaucier. 2002. Disponível em: <http://www.regroupement.net/10mai2002ARenaudConf.pdf>. Acesso em: 29 nov. 2013.

ROUDINESCO, E. Por que a psicanálise? Rio de Janeiro: Jorge Zahar, 2000.

SAFATLE, V. O poder da psiquiatria. Revista Cult, n. 184, 2013. Disponível em: <http://revistacult.uol.com.br/home/2013/10/o-poder-da-psiquiatria/>. Acesso em: 20 dez. 2013.

SIQUEIRA, E. S. E. A depressão e o desejo na psicanálise. Estudos e pesquisa em psicologia, n. 7(1), 2007, p. 71-80.

SOLER, C. O que Lacan dizia das mulheres (trad. V. Ribeiro). Rio de Janeiro: Jorge Zahar, 2006. SOLOMON, A. O demônio do meio-dia: uma anatomia da depressão. Rio de Janeiro: Objetiva, 2002.

TAVARES, L. A. T. A depressão como "mal-estar" contemporâneo: medicalização e (ex)-sistência dosujeito depressivo. São Paulo: Editora UNESP, 2010.

TEIXEIRA, M. A. R. Das neuroses de transferência às neuroses narcísicas: contribuições aos fundamentos da teoria freudiana da melancolia. Tese de doutorado. Programa de Pós-Graduação em Psicologia da Universidade Estadual Paulista de Assis, São Paulo. 2012. Inédita.

\section{Fernanda de Souza Borges}

\section{feborges.psi@gmail.com}

Paulo José da Costa

pjcosta@uem.br 